\title{
Chinese EFL University Students' Self-Reported Use of Vocabulary Learning Strategies
}

\author{
Sijing $\mathrm{Fu}^{1}$ \\ ${ }^{1}$ Department of Linguisitics and Translation, City University of Hong Kong, Hong Kong, China \\ Correspondence: Sijing Fu, Department of Linguisitics and Translation, City University of Hong Kong, Hong \\ Kong, China.
}

Received: November 2, 2021

Accepted: November 23, 2021

Online Published: November 26, 2021

doi: $10.5539 /$ elt.v14n12p117

URL: https://doi.org/10.5539/elt.v14n12p117

\begin{abstract}
This study conducted the semi-structured interview to investigate the types of vocabulary learning strategies (VLSs) Chinese English major university students employed and the factors for their VLS use. Chinese EFL learners frequently employed determination and cognitive strategies. They mainly used the mechanical strategies and focused on English words' meanings based on Chinese equivalents. They preferred bilingual dictionaries, repetition, and memorization of fixed examples involving news words. They used metacognitive and memory strategies less frequently. This study proposed that Chinese EFL students' rote memorization of English vocabulary was due to Chinese culture of learning, which values knowledge authority, consolidation and foundation, and also effort and perseverance. Additionally, the less L2 English immersion including L1 Chinese environment and non-communicative EFL environment also leads to Chinese EFL students' VLSs use. Therefore, it is suggested that students be encouraged to use more memory strategies and metacognitive strategies. English teachers should provide students with strategy instructions and guide students to learn vocabulary through different types of VLSs in classes. After class, students could be encouraged to learn vocabulary incidentally through both intensive and extensive reading.
\end{abstract}

Keywords: vocabulary learning strategies (VLSs), mechanical strategies, memorization, strategy instruction

\section{Introduction}

Because learning vocabulary is equated with acquiring vocabulary knowledge, vocabulary knowledge acquisition is indispensable (Schmitt, 2010); learners' lack of it is an obstacle to second-language (L2) learning. In terms of students' choices of VLSs, there is a controversial debate on the Chinese traditional way of vocabulary learning (Biggs, 1996; Gu, 2003). Memorization is perceived as a mechanical vocabulary learning approach without understanding. Whether this statement is true or not needs to be further explored. Therefore, the present study attempts to find the main reasons for Chinese EFL students' VLSs use. In this way, this study aims to make contribution to the controversial debate on whether memorization, the traditional way of vocabulary learning, is considered as a mechanical learning approach without understanding. In addition, teachers could become familiar with and have better understanding of students' vocabulary learning behaviors and then develop the most suitable vocabulary acquisition instruction.

\section{Literature Review}

\subsection{Taxonomy of Vocabulary Learning Strategies (VLSS)}

VLSs play a dominant role in tackling vocabulary learning problems at the stages of vocabulary acquisition. VLSs is the knowledge about the mechanisms as well as steps or actions to find out the vocabulary's meanings, retain and retrieve vocabulary, and use them (Catalan, 2003). The framework of VLSs in this study is based on Oxford (1990), O'Malley and Chamot (1990), and Schmitt (1997). The Table 1 below presents a summary of these strategies. 
Table 1. Categorisations and classifications of VLSs

\begin{tabular}{|c|c|}
\hline \multirow{2}{*}{\multicolumn{2}{|c|}{$\begin{array}{l}\text { Categories } \\
\text { Discovering words' meanings }\end{array}$}} \\
\hline & \\
\hline \multicolumn{2}{|c|}{ Determination strategy (DET) } \\
\hline \multicolumn{2}{|c|}{ vocabulary lists in textbooks, flashcards } \\
\hline \multicolumn{2}{|c|}{ bilingual or monolingual dictionaries } \\
\hline \multicolumn{2}{|c|}{ understand the new words through their Chinese equivalents } \\
\hline \multicolumn{2}{|c|}{ make guesses, analyse roots and affixes and parts of speech } \\
\hline \multicolumn{2}{|c|}{ Social /Affective Strategy 1 (SOC/AFF 1) } \\
\hline \multicolumn{2}{|c|}{ Work in groups, ask teachers or classmates } \\
\hline \multicolumn{2}{|c|}{ talk to myself to feel less stressed } \\
\hline \multicolumn{2}{|c|}{ give myself a reward, encourage myself } \\
\hline \multicolumn{2}{|c|}{ Consolidating word knowledge } \\
\hline \multicolumn{2}{|c|}{ Cognitive Strategy (COG) } \\
\hline \multirow{2}{*}{ Repetition } & Oral repetition, Visual/written repetition \\
\hline & Write the words and Chinese equivalents repeatedly \\
\hline Source & vocabulary lists, flashcards, vocabulary notebook \\
\hline Practising & listen to the English tape, do spelling exercise \\
\hline Patterns & setting phrases and collocations, idiom words \\
\hline Note-taking & meaning-oriented /use-oriented \\
\hline \multicolumn{2}{|c|}{ Memory Strategy (MEM) } \\
\hline \multirow[t]{2}{*}{ Grouping } & roots and affixes, types of words: grammatical class \\
\hline & similar letters in spelling (e.g. big, bag, bug) \\
\hline \multirow[t]{3}{*}{ Association } & associate words with Chinese having similar sounds synonyms and antonyms \\
\hline & keyword method, semantic maps \\
\hline & compose sentences with the new words \\
\hline Contexts & examples in contexts, string words into a storyline \\
\hline \multirow[t]{3}{*}{ Images and sounds } & words' relevant images, Configurations \\
\hline & words' location, use rhymes \\
\hline & practise words' sounds, visualise spelling \\
\hline Actions & physical sensation to words, physically act out words \\
\hline \multicolumn{2}{|c|}{ Metacognitive Strategy (MET) } \\
\hline \multicolumn{2}{|c|}{ regular reviews, plan a schedule } \\
\hline \multicolumn{2}{|c|}{ give attention to vocabulary learning } \\
\hline \multicolumn{2}{|c|}{ notice mistakes, test myself } \\
\hline \multicolumn{2}{|c|}{ think about vocabulary learning progresses } \\
\hline \multicolumn{2}{|c|}{ Social /Affective Strategy 2 (SOC/AFF 2) } \\
\hline \multicolumn{2}{|c|}{ teacher checks, ask teachers } \\
\hline \multicolumn{2}{|c|}{ study and practice words in a group } \\
\hline \multicolumn{2}{|c|}{ talk to myself to feel less stressed } \\
\hline give myself a rewar & ncourage myself \\
\hline
\end{tabular}




\subsection{Research Studies on EFL Students' Use of VLSs}

Based on the research studies (Asgari \& Mustapha, 2011; Gu \& Johnson, 1996; Lip, 2009; Subasi, 2014; Yazdi \& Kafipour, 2014), guessing words' meanings from contexts and using dictionaries were often used by EFL learners from Iran, Malaysia, Turkey and China. According to Asgari and Mustapha (2011) and Yazdi and Kafipour (2014), Iranian and Malay students particularly frequently used a monolingual dictionary (English to English). Subasi (2014) concluded that Turkish learners used more meaning-oriented strategies than rote strategies. As for Chinese learners, Gu and Johnson (1996) reported that they also preferred taking notes on words' meaning-oriented information. Instead of meaning-oriented strategies, Chinese students often used verbal or written repetition in other studies (Gu \& Johnson, 1996; Lip, 2009). Thus, mechanical strategies tend to be more popular among Chinese students than among foreign learners. Chinese learners are characterized by relying more on rote-based strategies (Li \& Cutting, 2011). Chinese students believe in the effectiveness of mechanical methods because students are influenced by the Confucian culture of learning, which advocates recitation, practice, and hard work (Li \& Cutting, 2011). Furthermore, there are contradictory perceptions of the features of Chinese students' VLS use. On one hand, traditional values of learning emphasize reflective thinking and that memorization is not equated with rote memorization (On, 1996). Li and Cutting (2011) further showed that strategies used by Chinese students to learn vocabulary relate to understanding. Conversely, Biggs (1996) and $\mathrm{Gu}$ (2003) contended that Chinese students use rote-based strategies without thinking about meaning. Therefore, whether Chinese EFL students use more rote-based strategies and whether their vocabulary learning is connected to understanding will be further explored in the present study.

\section{The Present Study}

The present study aimed to find out the types of VLSs used by Chinese EFL students and the reasons for using these types. There are two main questions in this study:

1) What types of VLSs do Chinese EFL students report they use?

2) What are the factors affecting Chinese EFL students' use of VLSs?

\section{Research Methodology}

\subsection{Participants}

The sampling of this study was 8 Chinese EFL university students from a university in mainland China, aging from 21 to 25. All their majors are English.

\subsection{The Semi-Structured Interview}

We used the semi-structured interview to explore students' use of VLS types and the factors affecting their use. Lip (2009) conducted structured interviews with much more targeted and specific questions, which resulted in focusing on only one aspect of the VLS use factors. Additionally, targeted questions tend to be misleading; instead, short, simple questions that contain one main idea work best (Dornyei, 2011). Conversely, Sinhaneti and Kyaw (2012) focused on semi-structured interviews without targeted questions. However, they also focused only on students' cultural beliefs, one of the factors influencing the use of VLSs. Therefore, to further analyze the factors for students' VLS use from more aspects and give the participants more freedom of expression, the present study adopted individual semi-structured interviews with both general questions and several follow-up questions.

In the interview, there were three general questions involving participants' vocabulary-learning purposes, VLS use, attitudes toward these strategies, and vocabulary learning problems. Additionally, the interview was conducted in L1 Chinese; in this way, participants could feel less stressed and avoid being unable to express themselves in English. Each interview lasted about 20 minutes and was recorded. These recordings were transcribed and translated into English.

\subsection{Data Analysis}

We used thematic analysis in the individual semi-structured interviews, which is defined as a method for identifying, analyzing, and reporting patterns within qualitative data (Clarke \& Braun, 2017). Consistent with both theory and prior studies, these potential themes were categorized into several areas: Chinese English major students' cultural beliefs about VLSs, vocabulary learning motivation, vocabulary learning environment, and vocabulary learning problems. Finally, we conducted ongoing analysis to generate clear explanations for each theme according to what was obtained from the data. 


\section{Results and Analysis}

According to the interview data, Table 2 generally presents the reasons for students' VLSs use.

Table 2. Main factors for students' total use of VLSs

\begin{tabular}{ll}
\hline Factors & Frequency of statements \\
\hline Positive attitude: learning vocabulary intentionally & 6 \\
Non-communicative English classes & 4 \\
L1 environment & 5 \\
Learning style is traditional & 2 \\
Exam-oriented learning system & 8 \\
\hline
\end{tabular}

The following section presents participants' most and least frequently used vocabulary learning strategies and the reasons for applying them. Table 3 demonstrates the types of VLSs applied most often by students.

Table 3. The most frequently-used VLSs

\begin{tabular}{ll}
\hline \multicolumn{2}{l}{ Categories and abbreviated statements } \\
\hline COG & oral repetition \\
COG & written repetition \\
DET & bilingual dictionaries \\
DET & guessing words \\
SOC/AFF & Talk to yourself to feel less stressed \\
DET & Chinese equivalents \\
COG & meaning-oriented note-taking \\
MEM & practising the sounds of words \\
COG & fixed phrases and collocations \\
MEM & example sentences with words \\
MEM & visualising spelling \\
\hline
\end{tabular}

Specifically, as demonstrated in Table 3,11 of 56 strategy items were the most popular among students. Of the 11 strategies, most, such as written and oral repetition, notetaking, practicing words' written and oral forms, and memorizing fixed examples, were mechanical. Furthermore, responses of all the participants $(\mathrm{N}=8)$ demonstrate they learned and memorized words' Chinese definitions. For example,

"When I encounter a new word, I check up the dictionary and write down the Chinese definitions beside a word". (S2)

"I take notes of words and their Chinese equivalents in the notebook". (S3)

"I keep words' Chinese equivalents in mind while I am seeing the new words repeatedly". (S5)

"While I am writing down new words several times, I am also thinking of words' Chinese definitions at the same time". (S6)

The reasons for why students were characterised in using these 11 vocabulary learning behaviours most frequently are further explored.

Table 4. Main factors for students' the most frequently-used VLSs

\begin{tabular}{ll}
\hline Factors & Frequency of statements \\
\hline Positive attitude: learning vocabulary intentionally & 6 \\
Non-communicative English classes & 4 \\
L1 environment & 5 \\
Learning style is traditional & 2 \\
The value of Knowledge authority and accuracy & 4 \\
The value of perseverance and effort & 7 \\
The value of foundation and consolidation & 7
\end{tabular}

First, as shown in Table 4, students most often tried to reduce their stress when learning vocabulary. This can be explained by students' positive perceptions of vocabulary acquisition. According to the interview data, to pass 
examinations and understand the English courses' reading materials, students were positively motivated to learn vocabulary, even though they still had vocabulary learning difficulties. Second, students most frequently used bilingual dictionaries to find the new words' meanings and understood words through Chinese equivalents. These results are a result of the EFL learning environment. Students $(\mathrm{N}=5)$ reported that they were involved in noncommunicative English classes and the L1 environment, in which English use was restricted. For instance,

"In English classes, we seldom use English to answer the questions. Teachers seldom guide us to acquire techniques to learn vocabulary either". (S1)

"There is a lack of group discussions and strategy instructions in classes. Teachers only have brief introduction of word knowledge". (S4)

"Our surroundings are Chinese-oriented and we seldom use English vocabulary we have memorised in daily life, such as communication. Words were forgotten quickly without applying them". (S6)

In addition, the values of knowledge, authority, and accuracy also result in students' using dictionaries. Four students said they highly trusted in a dictionary because information in dictionaries is considered authorized and comprehensible. For example,

"Dictionaries can provide comprehensible and accurate information that the authorised scholars have already concluded. It is better than knowing words through analysing and summarising by myself". (S3)

"Dictionaries are characterised by authorised content and accurate explanations for words. They are reliable". (S8)

Third, students' frequent use of mechanical strategies such as rehearsal, repetition, notetaking, and memorization of fixed examples is also explained by their cultural beliefs or values, which represent Chinese learning culture. In general, reflecting traditional learning style, respondents in the interviews had positive attitudes toward these mechanical methods. Being influenced by the Chinese cultural belief that authority and accuracy of knowledge are essential, students attached great importance to memorizing examples:

"Fixed word collocations must be obtained from dictionaries". (S3)

"Set phrases are authorised and accurate. They have been synthesised and put into practice. It is time-saving to directly copy them". (S8)

There are the other two aspects of the Chinese culture of learning that determine students' use of rote-based strategies. An interesting result from the interview data is that participants' responses were relevant to these words: "insisting," "hard-working and success," "down-to-earth," and "consolidating memory." Their responses were grouped into two themes: 1) effort and perseverance and 2) consolidation and foundation. First, students' repetition of words' spelling and pronunciation indicates that believe that effort and perseverance result in success and that perseverance is the key to vocabulary learning. Students $(\mathrm{N}=7)$ contended that the retention of words could be consolidated and deepened by insisting on word repetition.

Students most frequently practiced pronunciation and spelling of words because students place high value on the foundation of knowledge and consolidating knowledge. Seven students in the interviews believed that words should be learned from their basic elements, such as their spoken and written forms, and that writing could strengthen vocabulary knowledge:

"The palest ink is better than the best memory". (S1)

"Vocabulary should be memorised in a down-to-earth way by writing and speaking. In this way, we can have strong memory of words". (S8)

Table 5. shows the types of the least frequently used VLSs

\begin{tabular}{ll}
\hline Categories and abbreviated statements \\
\hline MEM & string words into storyline \\
DET/COG & flashcards \\
SOC/AFF & study words in a group \\
MEM & physically act out words \\
COG & listen to English tape \\
SOC/AFF & ask teachers of synonyms \\
MEM & semantic maps \\
MEM & associate words with similar sounds in Chinese \\
\hline
\end{tabular}


Table 5 shows the eight strategies that were used least often by students. Specifically, students ignored memory strategies involving using a semantic map, stringing words into a storyline, acting out words, and associating words with similar sounds in Chinese. Furthermore, although students preferred most cognitive strategies (as discussed in the previous section), using flashcards and listening to English tapes were the exceptions. The metacognitive strategies were most unpopular among students.

As demonstrated in Table 6, these results are explained by the exam-oriented learning system and the EFL learning environment.

Table 6. Main factors for students' the less and the least frequently-used VLSs

\begin{tabular}{ll}
\hline Factors & Frequency of statements \\
\hline L1 environment & 5 \\
Exam-oriented learning system & 8 \\
\hline
\end{tabular}

Students only needed to memorize the words' definitions to complete reading tasks and to pass exams. They were surrounded by the Chinese language and seldom used English for communication. For example,

"We are required to have a large number of vocabulary for examinations, it is time-consuming and troublesome to use semantic map, flashcards and storylines." (S4)

"I sometimes learn words through watching English TV programs and motives to learn authentic expressions". (S5)

\section{Discussion}

\subsection{Types of VLSS Used by Chinese EFL University Students}

In our study Chinese EFL students most often relied on mechanical strategies although they attempted to use a variety of VLSs. Their vocabulary learning was rote-based, and they paid more attention to words' meanings according to the Chinese equivalent. They most frequently employed 1) oral and visual repetition, 2) repetition of words' spellings and sounds, 3) the meaning-oriented notetaking, 4) memorization of fixed phrases and sentences with new words, and 5) words' Chinese equivalents. This finding is related to the view that Chinese students prefer rote-based strategies for vocabulary acquisition (Li \& Cutting, 2011; Tan, 2011).

The study found that students ignored metacognitive and memory strategies, the least frequently used VLSs. Specifically, similar to the study of Yazdi and Kafipour (2014), in which flashcards and word lists were unpopular, the present study finds that flashcards and word lists are also less frequently used by Chinese students. Additionally, the study confirms the findings of Yazdi and Kafipour (2014) that EFL learners seldom test themselves. Furthermore, students in this study rarely associated single words with semantic maps or linked the words into sentence contexts while learning them.

\subsection{Factors for Chinese EFL Students' Use of VLSs}

In general, students' English vocabulary learning behaviors are affected by the Chinese culture of learning and the lack of a native-like English learning environment. First, students in the study most frequently used mechanical strategies because they were influenced by the traditional Confucian-heritage cultures of learning. The result corroborates the findings of Gu (2003), Li and Cutting (2011), and Lip (2009) that cultural beliefs regarding learning affect Chinese EFL students' use of rote learning strategies. Based on the introduction of the Chinese culture of learning (Cortazzi \& Jin, 1996, 2013; Yuan \& Xie, 2013), the study shows the importance of authority and accuracy in knowledge, effort, and perseverance and that foundation and consolidation are attributable to Chinese students' VLS use. Similar to Gu (2003) and Lip (2009), who mentioned the importance of effort and perseverance, students in this study frequently employed oral and visual repetition, repeated a word's spelling and sounds, and took notes on words because they believe that effort and diligence are valuable to successful learning. Students in this study also highly valued knowledge consolidation. They believed that the basic elements of knowledge are primary and that learning should be down-to-earth, and they also believed that "practicing makes perfect" and that "writing is better than good memory." Therefore, being influenced by these beliefs, students most frequently used repetition and repeated words' spoken and written forms. They also attach importance to the value of the authority and accuracy of knowledge. Because of this belief, they often used bilingual dictionaries and memorized fixed phrases and example sentences. The traditional Chinese culture of learning influences students' most often-utilized strategies, the determination and cognitive strategies, in other words, the rote-based memorization of English words. 
Second, the study reveals that the lack of an authentic English learning environment and the noncommunicative language environment made students learn words' meanings according to their Chinese meanings and ignore several memory and social/affective strategies. In the Chinese context, students depended on Chinese, their mother tongue. Influenced by noncommunicative EFL classes, Chinese EFL students rely more on the Chinese equivalents to learn words and seldom applied English words in the classroom or in daily communication. They less frequently used memory strategies to understand words' grammatical forms and use constraints and therefore could not achieve the productive knowledge of word use.

\section{Conclusion and Recommendations}

This study concluded that Chinese EFL students exemplified rote-based vocabulary learning. They memorized English words by Chinese equivalents, oral and visual repetition, spelling, and notetaking. They seldom used metacognitive and memory strategies. The Chinese culture of learning and the less native-like English speaking environment affected Chinese EFL students' choices of VLSs.

Findings in this study provide implications for L2 lexical acquisition. Memory strategies such as composing sentences with new words and analyzing words' grammatical forms should be included in these students' strategies. In addition, intentional and incidental learning could be combined in vocabulary acquisition. For example, because reading is effective in vocabulary acquisition, intensive reading activities could be organized in EFL classrooms. Outside of class, additional extensive readings are also needed. It would be better if these extensive reading materials included repeated appearances of the learned words so that students could know and remember them naturally. Furthermore, natural exposure in L2 English is important. Students should learn words through authentic magazines, movies, etc. In addition, the English classroom environment should be communicative. For example, group discussions in English and creating situational English conversations could be organized in classes. In this way, students would learn social/affective strategies naturally and acquire greater word use knowledge.

\section{References}

Asgari, A., \& Mustapha, G. B. (2010). The type of vocabulary learning strategies used by ESL students in university Putra Malaysia. English Language Teaching, 4(2), 84-90.

Biggs, J. (1996). Western misperceptions of Confucian-heritage learning culture. In D. A. Watkins \& J. B. Biggs (Eds.), The Chinese Learner: Cultural psychological and contextual influence (pp. 45-67). Hong Kong: CERC and ACER.

Catalan, R. M. J. (2003). Sex differences in L2 vocabulary learning strategies. International Journal of Applied Linguistics, 13(1), 54-77. https://doi.org/10.1111/1473-4192.00037

Clarke, V., \& Braun, V. (2017). Thematic analysis. The Journal of Positive Psychology, 12(3), 297-298. https://doi.org/10.1080/17439760.2016.1262613

Cortazzi, M., \& Jin, L. (2011). Cultures of learning: Language classrooms in China. In H. Coleman (Ed.), Society and the language classroom (pp. 169-206). Cambridge, UK: Cambridge University Press.

Cortazzi, M., \& Jin, L. (2013). Researching cultures of learning: International perspectives on language learning and education. Palgrave Macmillan. https://doi.org/10.1057/9781137296344

Dornyei, Z. (2011). Research methods in applied linguistics. Oxford, UK: Oxford University Press.

Gu, P. Y. (2003). Fine brush and freehand: The vocabulary-learning art of two successful Chinese EFL learners. TESOL Quarterly, 37(1), 77-104. https://doi.org/10.2307/3588466

Gu, Y., \& Johnson, R. K. (1996). Vocabulary learning strategies and language learning outcomes. Language Learning, 46(4), 643-679. https://doi.org/10.1111/j.1467-1770.1996.tb01355.x

Li, X., \& Cutting, J. (2011). Rote learning in Chinese culture: Reflecting active Confucian-based memory strategies. In M. Cortazzi \& L. Jin (Eds.), Researching Chinese learners: skills, perceptions and intercultural adaptations (pp. 21-42). Basingstoke, UK: Palgrave Macmillan. https://doi.org/10.1111/j.1467-1770.1996.tb01355.x

Lip, P. C. H. (2009). Investigating the most frequently used and most useful vocabulary language learning strategies among Chinese EFL postsecondary students in Hong Kong. Electronic Journal of Foreign Language Teaching, 6(1), 77-87.

O’Malley, J., \& Chamot, A. (1990). Learning strategies in second language acquisition. Cambridge, UK: Cambridge University Press. https://doi.org/10.1017/CBO9781139524490 
On, W. L. (1996). The cultural context for Chinese learners: Conceptions of learning in the Confucian tradition. In, D. A. Watkins \& J. B. Biggs (Eds.), The Chinese learner: Cultural psychological and contextual influence (pp. 25-41). Hong Kong: CERC and ACER.

Oxford, R. L. (1990). Language learning strategies: What every teacher should know. Boston, Massachusetts: Heinle \& Heinle Publishers.

Schmitt, N. (1997). Vocabulary learning strategies. In N. Schmitt \& M. McCarthy (Eds.), Vocabulary: Description, acquisition and pedagogy (pp. 199-227). Cambridge, UK: Cambridge University Press.

Schmitt, N. (2010). Vocabulary in language teaching. Cambridge, UK: Cambridge University Press.

Sinhaneti, K., \& Kyaw, E. K. (2012). A study of the role of rote learning in vocabulary learning strategies of Burmese students. US-China Education Review, 2012(12), 987-1005.

Subasi, G. (2014). Vocabulary learning beliefs and strategies of Turkish ELT students. Online International Journal of Arts and Humanities, 7(3), 91-104.

Yazdi, M., \& Kafipour, R. (2014). A qualitative study of vocabulary learning strategies applied. by Iranian undergraduate EFL learners in real learning setting. English Language Teaching, 7(7), 1-7. https://doi.org/10.5539/elt.v7n7p1

Yuan, Y., \& Xie, Q. (2013). Cultures of learning: An evolving concept and an expanding. field. In M. Cortazzi \& L. Jin (Eds.), Researching cultures of learning: International perspectives on language learning and education (pp. 21-40). Palgrave Macmillan. https://doi.org/10.1057/9781137296344_2 


\section{Appendix}

\section{Interview schedule (Chinese version)}

个人信息:

姓名：性别：年级：

主要问题

学习词汇的目的

Vocabulary leaning purposes

为什么要学习英语词汇? 是处于什么目的呢?

\section{词汇学习策略}

\section{Vocabulary learning strategies}

你在学习英语词汇时都运用什么策略? 为什么? 你对这些策略有什么看法?

\section{词汇学习困难}

在你学习英语词汇的时候你会遇到困难吗? 如果会, 那具体有什么困难?

跟进问题:

你会定期地使用你说的那些方法吗?

你觉得这些方法对于你的词汇学习有效吗?

你还知道其他有关学习词汇有用的策略吗?

对于你的这些学习词汇的问题? 你有解决办法吗? 如果有, 是什么?

\section{Interview schedule (English version)}

Personal background information:

Name: Gender: Grade:

\section{Main questions}

Vocabulary leaning purposes

Why do you want to learn English vocabulary? For what purposes?

Vocabulary learning strategies

What strategies or behaviors do you use to learn English vocabularies and why?

Vocabulary learning problems

What problems do you have when learning English vocabulary? If any, what are they?

\section{Follow-up questions}

Do you use these strategies regularly?

Do you think that these strategies are effective for your vocabulary learning?

Do you know the other strategies that are helpful to vocabulary learning?

Do you have solutions to vocabulary learning problems? If any, what are they?

\section{Copyrights}

Copyright for this article is retained by the author(s), with first publication rights granted to the journal.

This is an open-access article distributed under the terms and conditions of the Creative Commons Attribution license (http://creativecommons.org/licenses/by/4.0/). 